\title{
A quick relaxation exercise for people with chronic obstructive pulmonary disease: explorative randomized controlled trial
}

\author{
Eleonora Volpato ${ }^{12^{*}}$ (D), Paolo Banfi ${ }^{2}$ (D) Antonello Nicolini ${ }^{3}$ (D) and Francesco Pagnini ${ }^{1,4}$ (D)
}

\begin{abstract}
Background: People with Chronic Obstructive Pulmonary Disease (COPD) suffer from dyspnoea, which may be increased by anxiety. Previous studies suggest that relaxation techniques may have positive effects in pulmonary rehabilitation. The main aim of this study is to explore the clinical impact of a quick, one-session, relaxation training for people with COPD.
\end{abstract}

Methods: In this perspective, 38 participants with COPD were recruited and randomly assigned to listen to a relaxing audio or to watch a neutral stimulus, during their routine exams. Participants were assessed for psychological and physiological variables, analysed through non-parametric tests.

Results: Those who joined the relaxation training showed more positive outcomes about respiratory and cardiac assessments, as well as for state anxiety and positive affections, in comparison with the baseline and the control group.

Conclusions: Study results suggest that relaxation has a potential to produce improvements in respiratory and cardiac functions, together with a positive emotional effect and a reduction of anxiety.

Trial registration: ClinicalTrials.gov ID: NCT02698904. Record Registration: February 2016.

Keywords: Relaxation techniques, Quality of life, Pulmonary rehabilitation, Clinical psychology

\section{Background}

Chronic Obstructive Pulmonary Disease (COPD) is a complex, debilitating, and preventable lung condition, characterized by "persistent and progressive airflow limitation due to chronic inflammatory response in the airways and the lung to noxious particles or gases" with different degrees of impairment [1]. There is a progressive pulmonary function impairment that leads to a lower exercise tolerance and, in severe conditions, to the need for oxygen and possibly mechanical ventilation [2]. Other main symptoms of COPD include chronic cough, dyspnea, overproduction of sputum, wheezing, chest tightness, asthenia, weight loss, and anorexia [1]. All these symptoms have a negative impact on the quality of

\footnotetext{
* Correspondence: eleonora.volpato@unicatt.it

${ }^{1}$ Department of Psychology, Università Cattolica del Sacro Cuore, Largo A. Gemelli, 1, Milan, Italy

${ }^{2}$ IRCCS Santa Maria Nascente, Fondazione Don Carlo Gnocchi, Milan, Italy Full list of author information is available at the end of the article
}

life $[3,4]$. The prevalence of the diseases is increasing as there is an increasing exposure to risk factors [5-7]. In fact, it is estimated that COPD may become the third cause of death in the world by 2020 [8]. In this respect, in patients with advanced COPD and severe chronic hypoxemia refractory to maximal treatment with bronchodilator and anti-inflammatory drugs, smoking cessation and long-term oxygen therapy are the only two interventions that have unequivocally shown to reduce COPD mortality [1].

Pulmonary rehabilitation is very important at any stage of the disease, improving the ability to tolerate fatigue and dyspnea, with a beneficial effect on daily activities [9-12]. People with COPD are at risk of severe distress [13]. Depression and anxiety often appear together in these patients [14], even if the actual presence of psychological issues tends to be underestimated by the physicians [15]. Therefore, these aspects often remain

(c) The Author(s). 2018 Open Access This article is distributed under the terms of the Creative Commons Attribution 4.0 International License (http://creativecommons.org/licenses/by/4.0/), which permits unrestricted use, distribution, and 
untreated $[14,16,17]$, with negative effects on the quality of life $[18,19]$.

Relaxation techniques are psychophysiological procedures that promote somatic and cognitive distension, relieving from tensions. These techniques are widely used in rehabilitation and are very effective against anxiety and distress $[20,21]$. Both the physiological and the psychological effects of relaxation have a positive effect on people affected by pulmonary diseases [22], improving the oxygen saturation $[23,24]$ and promoting a reduction of anxiety and depression in people with COPD [25-27]. The cost-effectiveness of adding this technique to a rehabilitation program, however, is not clear [27, 28]. So far [29], relaxation training for people with COPD has often been tested in the mainframe of more general interventions (e.g., Cognitive Behavioral Therapy - CBT). We believe that a quick relaxation training, provided by an audio-guide right after their hospital exams, will promote positive emotions, reduce state anxiety and improve respiratory conditions. In this perspective, our aim is to investigate the feasibility of the relaxation technique's application for people with COPD, exploring its preliminary efficacy and effectiveness in a short time of implementation. To date, no study has looked at verifying the experience of a brief relaxation exercise impact breathing and psychological parameters in people with COPD in the context of a clinical visit.

\section{Methods}

\section{Study aims}

The main aim of this study is to explore the effectiveness, feasibility and acceptability of a quick, one-session, relaxation training for people with Chronic Obstructive Pulmonary Disease (COPD) in a short time of implementation.

\section{Design and setting of the study}

We conducted an explorative, two-arms, single-blind Randomized Controlled Trial (RCT) to test the shortterm effects of a one-session relaxation training based on mindful natural breathing on people with COPD. Thirty-eight subjects with COPD were recruited from the Respiratory Rehabilitation Unit of the Don Gnocchi Hospital, in Milan. The study was approved by the Don Gnocchi Foundation Ethical Committee. ClinicalTrials. gov ID: NCT02698904.

\section{Participants}

Inclusion criteria were defined as follow: diagnosis of COPD confirmed by a specialized physician; age above or equal to 18 years; inpatients or outpatients; basal $\mathrm{FEV}_{1} / \mathrm{FVC}<70 \%$ of reference values, using the standards established by Global Initiative for Chronic Obstructive Lung Disease (GOLD) [1]. Subjects were excluded in case of pregnancy, psychiatric disturbances, oncological diseases and comorbid states that determine an immunosuppressive condition.

Subjects who met the inclusions criteria were randomly allocated to two groups. A simple randomization and an allocation ratio 1:1 were adopted (Fig. 1).

Informed consent was obtained. At baseline assessment, as well as at the end of the intervention (soon after), patients were assessed both about their psychological state (psychometric questionnaires) and their pulmonary function and physiological conditions (spirometry, saturation level and heart rate). While assessed, participants were blinded to their assignment.

\section{Intervention}

Subjects in the experimental group (EG) listened to a relaxing audio track of the duration of $11 \mathrm{~min}$. The content of the audio track was a relaxation exercise based on the mindful natural breathing [30]. Instructions included becoming aware of the sensations of breathing, accepting them as they are at the present moment and non-judgmental awareness of mind wandering. Subjects laid down on a rigid but not hard bed, with a pillow, to facilitate muscle release, listening to the audio track with a pair of headphones. Instructions included focusing on the breathing mechanism, by purposefully paying attention to the breath, placing the left hand on the chest and the right on abdomen, improving the perception of torso movements. These exercises aim to increase the awareness of the respiratory process, leading to a relaxation response [31]. Relaxing music was played on the background. Subjects were advised to close their eyes.

Participants in the control group (CG), instead, watched a documentary movie that included neutral contents and the same duration of the relaxation audio, in a relaxing setting similar to the other group.

\section{Instruments \\ Physiological assessment}

We assessed COPD severity with the lung function test, detecting Forced Vital Capacity (FVC), Forced Expiratory Volume in the First Second $\left(\mathrm{FEV}_{1}\right)$, Tiffeneau-Pinelli Index $\left(\mathrm{FEV}_{1} / \mathrm{FVC}\right)$ with spirometer PONY FX (COSMED Srl, Rome, Italy). We also used the module Rocc Pony FX, which allows the measurement of airway resistance $(\mathrm{kPa} / \mathrm{l} / \mathrm{s})$ using the technique of interrupter resistance (Rint). Furthermore, we detected the heart rate and oxygen saturation using pulse oximeter, Pulsox 300i (Konica Minolta, Inc.). The criteria used to determine if the spirometry tests were performed to 


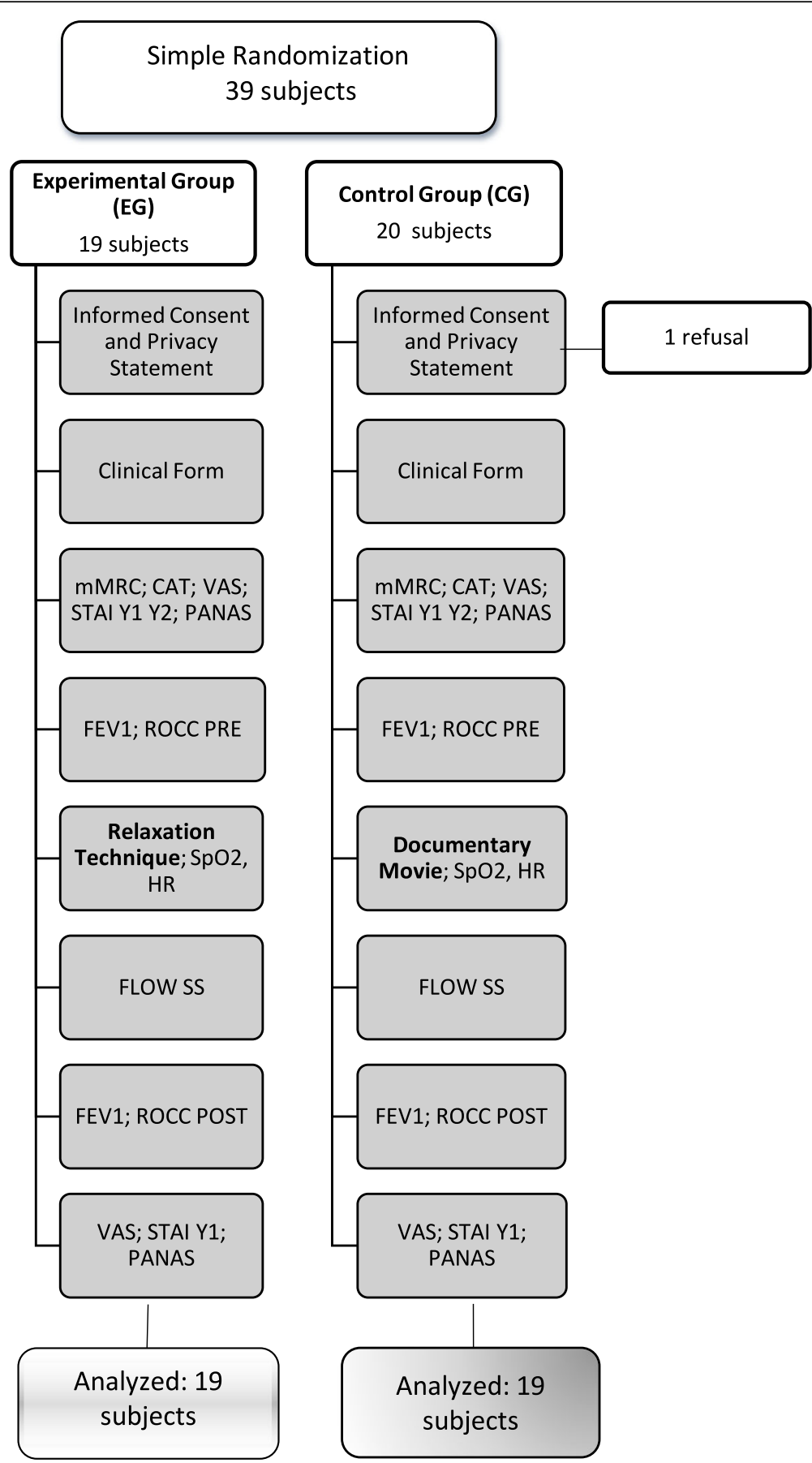

Fig. 1 Flow Chart of the procedure

an acceptable degree followed the Thoracic Society/ European Respiratory Society Statement [32].

State trait anxiety inventory - $Y 1$ and $Y 2$ forms (STAI- $Y 1$ Y2) The State-Trait Anxiety Inventory (STAI) is a self-report assessment device which includes separate measures of state and trait anxiety [33].
Positive and negative affective schedule (PANAS) (state version) The state version of Positive and Negative Affective Schedule (PANAS) was completed before and after treatment. It consists of 20 items, 10 for the scale of positive affect (PA) and 10 for the scale of negative affect (NA). The subject should evaluate his feelings with a five-point Likert scale. The original version was developed and validated by Watson, Clark and 
Table 1 Comparison of socio-demographic characteristics and baseline parameters of patients in overall sample, study and control groups $(p<0.05)^{a}$

\begin{tabular}{lll}
\hline Variables & $\begin{array}{l}\text { Experimental group } \\
(n=19)\end{array}$ & $\begin{array}{l}\text { Control group } \\
(n=19)\end{array}$ \\
\hline
\end{tabular}

Socio- demographic data

$\operatorname{Sex}(n, \%)$

Female

Male

Age (years) (Mean, SD)

Weight (Mean, SD)

Height (Mean, SD)

$\mathrm{BMI}^{\mathrm{b}}$ (Mean, SD)

Educational level $(n, \%)$

$\begin{array}{ll}\text { None } & 1(5.30) \\ \text { Primary School } & 7(36.80) \\ \text { Junior High School } & 7(36.80) \\ \text { High School } & 4(21.10) \\ \text { Graduated or higher education } & 0(0)\end{array}$

Profession/Job done longer in the past $(n, \%)$

Housewife
Employee
Laborer
Professional
Manager

Medical and clinical data

Duration of Illness (Mean, SD)

$$
5(n, \%)
$$

$10(n, \%)$

$>15(n, \%)$

Smoking $(n, \%)$

Never
Yes

Quitted

Drugs $(n, \%)$

LAMA $\left.\right|^{\mathrm{b}}$
$\left.\angle A B A\right|^{\mathrm{b}}$
$\mathrm{CS}^{\mathrm{b}}$
Anxiolytics
Antidepressants
Exacerbation, last year $(n, \%)$
$<1$
$1-3$
$>3$

$>3$
$4(21.10)$

$5(26.30)$

4 (21.05)

5 (26.30)

$1(5.30)$

7 (36.80)

12 (63.20)

$72.79(7.06)$

69.59 (13.24)

$165.26(10.13)$

$25.5(4.85)$

0 (0)

$9(47.40)$

$6(31.60)$

$3(15.80)$

1 (5.30)

$2(10.50)$

2 (10.50)

8 (42.10)

5 (26.30)

2 (10.50)

$2.26(0.80)$

$4(21.10)$

$6(31.60)$

9 (47.40)

$2(10.50)$

0 (0)

7 (36.80)

$12(63.20)$

$11(57.90)$

15 (78.90)

17 (89.50)

17 (89.5)

$12(63.20)$

18 (94.70)

$10(52.60)$

$9(47.40)$

4 (21.10)

$10(52.60)$

$9(47.40)$

$0(0)$
Table 1 Comparison of socio-demographic characteristics and baseline parameters of patients in overall sample, study and control groups $(p<0.05)^{\mathrm{a}}$ (Continued)

\begin{tabular}{cll}
\hline Variables & $\begin{array}{l}\text { Experimental group } \\
(n=19)\end{array}$ & $\begin{array}{l}\text { Control group } \\
(n=19)\end{array}$ \\
\hline $\begin{array}{l}\text { Hospitalization, last year }(n, \%) \\
<1\end{array}$ & $13(68.40)$ & $11(57.90)$ \\
2 & $5(26.30)$ & $8(42.10)$ \\
$>2$ & $1(5.30)$ & $0(0)$ \\
mMRC $^{c}$ & $2.47(0.51)$ & $2.21(0.41)$ \\
CAT $^{c}$ & 28.79 & 30.68
\end{tabular}

Data are presented as Mean+/-Standard Deviation (SD) and number, percentage $(n, \%)$

${ }^{\circ} B M I$ Body Mass Index, LAMA Long-Acting Muscarinic Antagonists, LABA Long-Acting Beta 2-Adrenergic Agonists, ICS Inhaled Corticosteroids ${ }^{\prime} m M R C$ Modified Medical Research Council Dyspnoea Scale, CAT COPD Assessment Test

Tellegen in 1988 and it possesses excellent psychometric properties [34].

\section{Visual analogue scales (VAS)}

Patients scored their emotional state on a Visual Analogue Scale (VAS), before and after the treatment. In particular, each subject was asked to rate on a range of 0-7 the intensity of its liveliness, sadness, anger, surprise, anxiety, repugnance, fury and serenity at the moment of the administration.

\section{Short flow state scale (short FSS-2)}

A short form of Flow State Scale, called Short FSS-2, was completed after treatment to assess the possible state of flow experience [35].

\section{Statistical analysis}

Data analysis was conducted with the statistical software Statistical Package for Social Science (SPSS). Given the relatively small sample and the expectation of a nonnormal distribution, we opted for the use of nonparametric tests. Differences between the two groups were analyzed with the Mann-Whitney $U$ test, while within analyses were conducted with the Wilcoxon test. The significance level was set to 0,05 .

\section{Results}

\section{Sample characteristics}

The study sample (see Table 1) was composed by 38 participants (23 males and 15 females), with a mean age of 72.66 years old. The mean length of illness was 2 . 03 years. All subjects had moderately severe chronic airflow limitations with an average $\mathrm{FEV}_{1}$ of $54.26 \%$ of the reference value and an average $\mathrm{FVC}$ of $72.11 \%$. 
Differences between groups before and after treatment After the treatment, we found significant differences (Table 2) in favor of the EG in comparison with the CG concerning heart rate $(\mathrm{U}=95, z=-2504, p=0.006)$. There were also significant differences between groups about both emotional states, assessed by VAS $(U=108$, $z=-2129, p=0.016)$, and anxiety state, detected by STAI-Y1 $(\mathrm{U}=104.5, z=2223, p=0.013)$.

\section{Analysis of the variables within groups before and after treatment}

Comparing pre-post intervention (Table 3), the detection of respiratory resistance allowed to detect notable differences only within the experimental group $(z=-$ $1851 p=0.032)$. Similarly, the heart rate had an important decrease in the EG $(z=-3576, p=0.000)$ and not in the CG $(z=-1776, p=0.038)$.

Regarding the psychological states, there was a significant change about the positive affects only within the experimental group $(z=-2581, p=0.005)$; while there was a significance change about the negative affections in both groups (experimental group: $z=-$ 3127, $p=0.001$; control group: $z=-3186, p=0.000$ ).

\section{Discussion}

We conducted a Randomized Control Trial to evaluate the impact of a relaxation technique on psychological and physiological well-being of people with COPD. The findings of this study suggest that a brief relaxation technique, based on mindful natural breathing, can be a helpful tool to improve psychological well-being and symptoms management of people with COPD. In particular, this mindful natural breathing improved the blood oxygenation load and FVC, as well as breathing resistance. That means, that respiratory levels improved after an 11-min guided relaxation training. This result supports the hypothesis that relaxation techniques can promote better blood oxygenation, in line with

Table 2 Comparison of psychological characteristics, pulmonary functions and other clinical data between groups at the end of the study $(p<0.05)^{\mathrm{a}}$

\begin{tabular}{|c|c|c|c|c|c|c|}
\hline \multirow[b]{2}{*}{ Variables } & \multicolumn{3}{|l|}{ Baseline } & \multicolumn{3}{|l|}{ Post - treatment } \\
\hline & $\begin{array}{l}\text { Experimental Group } \\
(\mathrm{EG} ; n=19)\end{array}$ & $\begin{array}{l}\text { Control Group } \\
(\mathrm{CG} ; n=19)\end{array}$ & $\begin{array}{l}\text { Mann-Whitney } \\
\text { Test } p(U, Z)\end{array}$ & $\begin{array}{l}\text { Experimental Group } \\
(E G ; n=19)\end{array}$ & $\begin{array}{l}\text { Control Group } \\
(\mathrm{CG} ; n=19)\end{array}$ & $\begin{array}{l}\text { Mann-Whitney Test } \\
p(U, Z)\end{array}$ \\
\hline \multicolumn{7}{|l|}{ Psychological states } \\
\hline STAI-Y1 ${ }^{\mathrm{b}}($ Mean +/- SD) & $33.68(6.48)$ & $36.68(10.26)$ & $\begin{array}{l}U=151.5 z=- \\
0.848 p=0.198\end{array}$ & $26.05(5.04)$ & $31.26(7.43)$ & $\begin{array}{l}U=104.5 z=-2223 \\
p=0.013^{*}\end{array}$ \\
\hline \multicolumn{7}{|l|}{ PANAS $^{\mathrm{b}}($ Mean $+/-$ SD) } \\
\hline Positive & $2.92(0.24)$ & $3.05(0.46)$ & $\begin{array}{l}U=159 z=- \\
0.633 p=0.2635\end{array}$ & $3.17(0.36)$ & $3.01(0.38)$ & $\begin{array}{l}U=139.5 z=-1202 \\
p=0.114\end{array}$ \\
\hline Negative & $1.39(0.48)$ & $1.45(0.43)$ & $\begin{array}{l}U=155 z=- \\
0.751 p=0.226\end{array}$ & $1.12(0.26)$ & $1.12(0.20)$ & $\begin{array}{l}U=161 z=-0.638 \\
p=0.261\end{array}$ \\
\hline VAS $^{\mathrm{b}}($ Mean $+/-S D)$ & $20.53(5.07)$ & $20.68(5.45)$ & $\begin{array}{l}U=173.5 z=- \\
0.206 p=0.418\end{array}$ & $19.79(3.76)$ & $17.68(3.95)$ & $\begin{array}{l}U=108 z=-2129 \\
p=0.016^{*}\end{array}$ \\
\hline FSS-2 $($ Mean $+/$-SD $)$ & & & & $33.63(3.74)$ & $33.57(3.06)$ & $\begin{array}{l}U=174 z=-0.191 \\
p=0.424\end{array}$ \\
\hline \multicolumn{7}{|l|}{ Psychological traits } \\
\hline STAI-Y2 ${ }^{\mathrm{b}}($ Mean+/- SD) & $36.63(11.96)$ & $39(11.04)$ & $\begin{array}{l}U=155 z=- \\
0.745 p=0.228\end{array}$ & & & \\
\hline \multicolumn{7}{|c|}{ Pulmonary functions and physiological data } \\
\hline $\mathrm{FEV}_{1}^{\mathrm{b}}($ Mean +/-SD) & $1.35(0.74)$ & $1.24(0.51)$ & $\begin{array}{l}U=175 z=- \\
0.161 p=0.436\end{array}$ & $1.39(0.75)$ & $1.26(0.47)$ & $\begin{array}{l}U=168.5 z=-0.350 \\
p=0.363\end{array}$ \\
\hline $\mathrm{FVC}^{\mathrm{b}}($ Mean $+/$-SD $)$ & $2.14(0.94)$ & $2.27(0.89)$ & $\begin{array}{l}U=167 z=- \\
0.394 p=0.346\end{array}$ & $1.97(0.93)$ & $2.38(0.81)$ & $\begin{array}{l}U=127 z=-1562 \\
p=0.059\end{array}$ \\
\hline $\begin{array}{l}\mathrm{ROCC}^{\mathrm{b}}, \mathrm{kPa} / \mathrm{l} / \mathrm{s} \\
(\text { Mean +/-SD) }\end{array}$ & $0.34(0.14)$ & $0.30(0.12)$ & $\begin{array}{l}U=151.5 z=- \\
0.847 p=0.198\end{array}$ & $0.40(0.19)$ & $0.30(0.15)$ & $\begin{array}{l}U=135.5 z=-1314 \\
p=0.094\end{array}$ \\
\hline $\mathrm{SpO}_{2}^{\mathrm{b}}$ (Mean +/-SD) & $91.63(3.18)$ & $95.58(2.79)$ & $\begin{array}{l}U=110.5 z=- \\
2058 p=0.020^{*}\end{array}$ & $93.84(2.73)$ & $94(2.62)$ & $\begin{array}{l}U=175.5 \quad z=-0.148 \\
p=0.441\end{array}$ \\
\hline $\mathrm{HR}^{\mathrm{b}}($ Mean+/-SD) & $69.32(8.80)$ & 73.95 (11.47) & $\begin{array}{l}U=140.5 z=- \\
1171 p=0.121\end{array}$ & $65.47(7.87)$ & 73.05 (11.75) & $\begin{array}{l}U=95 z=-2504 \\
p=0.006^{*}\end{array}$ \\
\hline
\end{tabular}

${ }^{a}$ Data are presented as Mean+/-Standard Deviation (SD) and number, percentage $(n, \%)$

${ }^{\mathrm{b}}$ STAI-Y1 State Trait Anxiety Inventory-State Form, PANAS Positive and Negative Affective Schedule-State Form, VAS Visual Analogue Scale, FSS-2 Short Flow State Scale 2, STAI-Y2 State Trait Anxiety Inventory-Trait Form, FEV 1 Forced Expiratory Volume in the First Second, FVC Forced Vital Capacity, ROCC, kPa/l/s Measurement of airway resistance, $\mathrm{SpO}_{2}$ Oxygen saturation, $\mathrm{HR}$ Heart Rate 
Table 3 Comparison of psychological characteristics, pulmonary functions and other clinical data at baseline and after treatments of patients both in study group and control group $(p<0.05)^{a}$

\begin{tabular}{|c|c|c|c|c|c|c|}
\hline \multirow[b]{2}{*}{ Variables } & \multicolumn{3}{|c|}{ Experimental group (EG; $n=19)$} & \multicolumn{3}{|c|}{ Control group (CG; $n=19)$} \\
\hline & Baseline & Post - treatment & Wilcoxon Test $z, p$ & Baseline & Post - treatment & Wilcoxon Test $z, p$ \\
\hline \multicolumn{7}{|l|}{ Psychological states } \\
\hline STAI-Y1 ${ }^{\mathrm{b}}($ Mean +/- SD) & $33.68(6.48)$ & $26.05(5.04)$ & $z=-3771 p=0.000^{*}$ & $36.68(10.26)$ & $31.26(7.43)$ & $z=-3010 p=0.001^{*}$ \\
\hline \multicolumn{7}{|l|}{ PANAS $^{\text {b }}$ (Mean +/- SD) } \\
\hline Positive & $2926(0.24)$ & $3.17(0.36)$ & $z=-2581 p=0.005^{*}$ & $3.05(0.46)$ & $3.01(0.38)$ & $z=-0.88 p=0.465$ \\
\hline Negative & $1395(0.48)$ & $1.12(0.26)$ & $z=-3127 p=0.001^{*}$ & $1.45(0.43)$ & $1.12(0.20)$ & $z=-3186 p=0.000^{*}$ \\
\hline VAS $^{\mathrm{b}}($ Mean +/-SD) & $20.53(5.07)$ & $19.79(3.76)$ & $z=-0.284 p=0.388$ & $20.68(5.45)$ & $17.68(3.95)$ & $z=-2605 p=0.004^{*}$ \\
\hline \multicolumn{7}{|l|}{ Psychological traits } \\
\hline STAI-Y2 ${ }^{\mathrm{b}}($ Mean+/- SD) & $36.63(11.96)$ & & & $39(11.04)$ & & \\
\hline \multicolumn{7}{|c|}{ Pulmonary functions and physiological data } \\
\hline $\mathrm{FEV}_{1}^{\mathrm{b}}($ Mean $+/$-SD $)$ & $1.35(0.74)$ & $1.39(0.75)$ & $z=-0.735 p=0.231$ & $1.24(0.51)$ & $1.26(0.47)$ & $z=-1702 p=0.044^{*}$ \\
\hline $\mathrm{FVC}^{\mathrm{b}}($ Mean $+/$-SD $)$ & $2143(0.94)$ & $1.97(0.93)$ & $z=-2378 p=0.008^{*}$ & $2.27(0.89)$ & $2.38(0.81)$ & $z=-2335 p=0.010^{*}$ \\
\hline $\mathrm{ROCC}^{\mathrm{b}}, \mathrm{kPa} / \mathrm{l} / \mathrm{s}($ Mean +/-SD) & $0.34(0.14)$ & $0.40(0.19)$ & $z=-1851 p=0.032^{*}$ & $0.30(0.12)$ & $0.30(0.15)$ & $z=-0.362 p=0.358$ \\
\hline $\mathrm{vSpO}_{2}{ }^{\mathrm{b}}($ Mean +/-SD) & $91.63(3.18)$ & $93.84(2.73)$ & $z=-2672 p=0.004^{*}$ & $95.58(2.79)$ & $94(2.62)$ & $z=-1327 p=0.092$ \\
\hline $\mathrm{HR}^{\mathrm{b}}($ Mean+/-SD) & $69.32(8.80)$ & $65.47(7.87)$ & $z=-3576 p=0.000^{*}$ & $73.95(11.47)$ & $73.05(11.75)$ & $z=-1776 p=0.038^{*}$ \\
\hline
\end{tabular}

${ }^{\mathrm{a}}$ Data are presented as Mean+/-Standard Deviation (SD) and number, percentage $(n, \%)$

${ }^{b}$ STAI-Y1 State Trait Anxiety Inventory-State Form, PANAS Positive and Negative Affective Schedule-State Form, VAS Visual Analogue Scale, FSS-2 Short Flow State Scale 2, STAI-Y2 State Trait Anxiety Inventory-Trait Form, FEV Forced Expiratory Volume in the First Second, FVC Forced Vital Capacity, ROCC, kPa/l/s Measurement of airway resistance, $\mathrm{SpO}_{2}$ Oxygen saturation, $\mathrm{HR}$ Heart Rate

previous studies $[23,36]$. It is also reported a significant decrease in heart rate: this other data corroborates the results of previous works on relaxation techniques that have found a decrease in heart beats per minute [37].

The relaxation audio had a positive emotional effect, increasing positive affects and reducing negative affections, confirming the hypothesis and previously obtained results [37, 38]. Furthermore, anxiety was significantly reduced after the intervention, both in comparison with the baseline assessment and with the control group. This confirms the idea that relaxation is one of the main treatments for anxiety $[39,40]$.

Study results could be useful in the clinical practice and highly reproducible. The intervention was held in a single session and with the use of an audio-recorded relaxing track. Furthermore, this type of quick relaxation exercise could be useful during daytime activities of people with COPD, especially when they are alone or when anxiety emerges as a possible attack of dyspnea. Relaxation techniques can, in fact, be practiced at any time, even on their own. Furthermore, relaxation techniques can be incorporated into other interventions, helping to reduce anxiety and depression. Therefore, the inclusion of relaxation training in the clinical routine of pulmonary services with COPD could be easily accomplished and could provide positive effects. In fact, even if our study was limited by a single session of the intervention, it was able to alleviate anxiety and improve well- being, with a highly scalable approach. Nevertheless, it is also limited by its relatively small sample size. Furthermore, generalization of the results from this study is restricted by the participants' characteristics, who represented a narrow range of education levels, with basically no subjects with a graduate degree. The study was conducted in single-blind mode, therefore the researcher was aware of the group of the subject. Even if self-report and physiological assessments may be less influenced than other instruments, we recognize that limitation. Furthermore, it is possible to note that the main differences between groups are limited to the anxiety state and the dyspnea perceived as well as the heart rate, confirming that they are intrinsically related: indeed, sympathetic arousal is a physiological manifestation of anxiety. This result could also suggest the importance to improve the patient's education in practicing the technique in order to obtain more significant short-term effects. Finally, the study was conducted in the hospital, during regular exams, and therefore it is not generalizable outside this setting.

Future works may consider a larger and more representative sample, with assessments from multiple settings. Nonetheless, further studies are needed to investigate better the efficacy and effectiveness of a relaxation technique based on mindful natural breathing, taking advantages of more than one session, because a long-term practice could boost beyond the benefits. 
Motivation and concentration are essential in the practice of relaxation. These two elements require a certain level of patients' engagement, that can be stimulated by health practitioners. Our findings indicate that relaxation techniques could pay an important role in intervention strategies, contributing to an improvement of the QoL and the well-being of people with COPD. The possible impact of this use of relaxation training on health costs may deserve a future investigation.

\section{Conclusions}

The findings of our study show that a relaxation technique based on mindful natural breathing might have a potential to improve the COPD patients' overall well-being. In particular, mindful natural breathing induces significant improvements in respiratory and cardiac functions, together with a positive emotional effect and a reduction of anxiety. Although the present study is a short-term one and its conclusions must be confirmed by further studies, it was required before a long-term investigation, in order to examine the endurance and the utility of the treatment to the patients.

\section{Abbreviations \\ CBT: Cognitive Behavioral Therapy; CG: control group; COPD: Chronic Obstructive Pulmonary Disease; EG: experimental group; $\mathrm{FEV}_{1}$ : Forced Expiratory Volume in the First Second; FEV $1 / F V C$ : Tiffeneau-Pinelli Index; FVC: Forced Vital Capacity; GOLD: Global Initiative for Chronic Obstructive Lung Disease; NA: negative affect; PA: positive affect; PANAS: Positive and Negative Affective Schedule; RCT: Randomized Control Trial; Short FSS- 2: Short Flow State Scale; SPSS: Statistical Package for Social Science; STAI: State-Trait Anxiety Inventory; VAS: Visual Analogue Scales}

\section{Acknowledgements}

The abstract of this paper was presented at the International Conference on Studies in Humanities and Social Science (SHSS-2015), ERPUB 2015, Paris (France) as a conference talk with interim findings. The poster's abstract was published in "Poster Abstracts" in International Conference on Studies in Humanities and Social Sciences (SHSS-2015) (pp. 317-425). Plaisent Michel; Zheng Lili.

\section{Ethics approvals and consent to participate}

The study was approved by the Comitato Etico Centrale IRCCS Regione Lombardia, at IRCCS Santa Maria Nascente, Fondazione Don Carlo Gnocchi, Milan (Italy) (Ethical Committee) on 15 th October 2013.

\section{Funding}

No funding was provided for this study.

\section{Availability of data and materials}

The datasets used and/or analysed during the current study are available from the corresponding author on reasonable request.

\section{Authors' contributions}

EV developed and carried out the study. PB and AN aided in interpreting the results and revised the manuscript. FP supervised the entire research. All the authors contributed to and approved the final manuscript.

\section{Consent for publication}

Each participant was informed about the study details and procedure and receive both a leaflet about the study and an institutional Consent Form. There were also the contacts of the investigators to ask for more information if they wished. Participants who consented to take part to the study, had the opportunity to ask for further information and to discuss and consent for participation in a face to face meeting with the investigator.

\section{Competing interests}

The authors declare that they have no competing interests.

\section{Publisher's Note}

Springer Nature remains neutral with regard to jurisdictional claims in published maps and institutional affiliations.

\section{Author details}

${ }^{1}$ Department of Psychology, Università Cattolica del Sacro Cuore, Largo A. Gemelli, 1, Milan, Italy. ${ }^{2}$ IRCCS Santa Maria Nascente, Fondazione Don Carlo Gnocchi, Milan, Italy. ${ }^{3}$ Unità di Riabilitazione Respiratoria, ASL 4 Chiavarese, Ospedale di Sestri Levante, Sestri Levante, Italy. ${ }^{4}$ Department of Psychology, Harvard University, Cambridge, MA, USA.

Received: 14 February 2018 Accepted: 4 April 2018

Published online: 02 May 2018

\section{References}

1. GOLD. Global Strategy for the Diagnosis, Management and Prevention of COPD, Global Initiative for Chronic Obstructive Lung Disease (GOLD) 2016 [Internet]. 2016. Available from: http://goldcopd.org.

2. Fabbri LM, Hurd SS. GOLD scientific committee. Global strategy for the diagnosis, management and prevention of COPD: 2003 update. Eur Respir J. 2003;22(1):1-2.

3. Arne M, Emtner M, Janson S, Wilde-Larsson B. COPD patients perspectives at the time of diagnosis: a qualitative study. Prim Care Respir J J Gen Pract Airw Group. 2007;16(4):215-21.

4. Wong CJ, Goodridge D, Marciniuk DD, Rennie D. Fatigue in patients with COPD participating in a pulmonary rehabilitation program. Int J Chron Obstruct Pulmon Dis. 2010;5:319-26.

5. Murray CJ, Lopez AD. Alternative projections of mortality and disability by cause 1990-2020: global burden of disease study. Lancet Lond Engl. 1997;349(9064):1498-504.

6. Johns MW. A new method for measuring daytime sleepiness: the Epworth sleepiness scale. Sleep. 1991;14(6):540-5.

7. Pauwels RA, Buist AS, Calverley PM, Jenkins CR, Hurd SS. GOLD scientific committee. Global strategy for the diagnosis, management, and prevention of chronic obstructive pulmonary disease. NHLBI/WHO global initiative for chronic obstructive lung disease (GOLD) workshop summary. Am J Respir Crit Care Med. 2001;163(5):1256-76.

8. Burney PGJ, Patel J, Newson R, Minelli C, Naghavi M. Global and regional trends in COPD mortality, 1990-2010. Eur Respir J. 2015;45(5):1239-47.

9. Berry MJ, Rejeski WJ, Adair NE, Zaccaro D. Exercise rehabilitation and chronic obstructive pulmonary disease stage. Am J Respir Crit Care Med. 1999;160(4):1248-53

10. Lacasse Y, Brosseau L, Milne S, Martin S, Wong E, Guyatt GH, et al. Pulmonary rehabilitation for chronic obstructive pulmonary disease. Cochrane Database Syst Rev. 2002;(3):CD003793.

11. Lacasse $Y$, Goldstein R, Lasserson TJ, Martin S. Pulmonary rehabilitation for chronic obstructive pulmonary disease. Cochrane Database Syst Rev. 2006;:CD003793.

12. Ries AL, Bauldoff GS, Carlin BW, Casaburi R, Emery CF, Mahler DA, et al. Pulmonary rehabilitation: joint ACCP/AACVPR evidence-based clinical practice guidelines. Chest. 2007;131(5 Suppl):4S-42S.

13. Wagena EJ, Arrindell WA, Wouters EFM, van Schayck CP. Are patients with COPD psychologically distressed? Eur Respir J. 2005;26(2):242-8

14. Kunik ME, Roundy K, Veazey C, Souchek J, Richardson P, Wray NP, et al. Surprisingly high prevalence of anxiety and depression in chronic breathing disorders. Chest. 2005;127(4):1205-11.

15. van den Boom G, van Schayck CP, van Möllen MP, Tirimanna PR, den Otter $J$ J, van Grunsven PM, et al. Active detection of chronic obstructive pulmonary disease and asthma in the general population. Results and economic consequences of the DIMCA program. Am J Respir Crit Care Med. 1998;158(6):1730-8.

16. Kim HFS, Kunik ME, Molinari VA, Hillman SL, Lalani S, Orengo CA, et al. Functional impairment in COPD patients: the impact of anxiety and depression. Psychosomatics. 2000;41(6):465-71.

17. Yohannes AM. Predictors of 1-year mortality in patients discharged from hospital following acute exacerbation of chronic obstructive pulmonary disease. Age Ageing. 2005;34(5):491-6. 
18. Bosley CM, Corden ZM, Rees PJ, Cochrane GM. Psychological factors associated with use of home nebulized therapy for COPD. Eur Respir J. 1996;9(11):2346-50.

19. Gudmundsson G, Gislason T, Janson C, Lindberg E, Suppli Ulrik C, Brøndum E, et al. Depression, anxiety and health status after hospitalisation for COPD: a multicentre study in the Nordic countries. Respir Med. 2006;100(1):87-93.

20. Manzoni GM, Pagnini F, Castelnuovo G, Molinari E. Relaxation training for anxiety: a ten-years systematic review with meta-analysis. BMC Psychiatry [Internet]. 2008;8(1). [cited 2016 Dec 10] Available from: http:// bmcpsychiatry.biomedcentral.com/articles/10.1186/1471-244X-8-41.

21. Pagnini F, Manzoni GM, Castelnuovo G, Molinari E. The efficacy of relaxation training in treating anxiety. Int J Behav Consult Ther. 2010;5(3-4):264-9.

22. Volpato E, Banfi P, Rogers SM, Pagnini F. Relaxation techniques for people with chronic obstructive pulmonary disease: a systematic review and a meta-analysis. Evid Based Complement Alternat Med. 2015;2015:1-22.

23. SW-S L. The effects of guided imagery relaxation in people with COPD. Occup Ther Int. 2004;11(3):145-59.

24. Moody LE, Fraser M, Yarandi $H$. Effects of guided imagery in patients with chronic bronchitis and emphysema. Clin Nurs Res. 1993;2(4):478-86.

25. Emery CF, Leatherman NE, Burker EJ, Mclntre NR. Psychological outcomes of a pulmonary rehabilitation program. Chest. 1991;100(3):613-7.

26. Garuti G, Cilione C, Dell'Orso D, Gorini P, Lorenzi MC, Totaro L, et al. Impact of comprehensive pulmonary rehabilitation on anxiety and depression in hospitalized COPD patients. Monaldi Arch Chest Dis. 2003;59(1):56-61.

27. Lolak S, Connors GL, Sheridan MJ, Wise TN. Effects of progressive muscle relaxation training on anxiety and depression in patients enrolled in an outpatient pulmonary rehabilitation program. Psychother Psychosom. 2008; 77(2):119-25.

28. Ries AL, Kaplan RM, Limberg TM, Prewitt LM. Effects of pulmonary rehabilitation on physiologic and psychosocial outcomes in patients with chronic obstructive pulmonary disease. Ann Intern Med. 1995;122(11):823-32

29. Cahalin LP, Braga M, Matsuo Y, Hernandez ED. Efficacy of diaphragmatic breathing in persons with chronic obstructive pulmonary disease: a review of the literature. J Cardiopulm Rehabil. 2002;22(1):7-21.

30. Payne RA, Donaghy M, Payne RA, Editors. Payne's handbook of relaxation techniques: a practical guide for the health care professional. 4th ed. Edinburgh; New York: Churchill Livingstone/Elsevier; 2010. 274 pe.

31. Benson HMD, Klipper MZ. The relaxation response. New York: Harper Collins; 1992

32. Miller MR, Hankinson J, Brusasco V, Burgos F, Casaburi R, Coates A, et al. Standardisation of spirometry. Eur Respir J. 2005;26(2):319-38.

33. Spielberger CD, Gorsuch RL, Lushene RE, Vagg PR. State-trait anxiety inventory (STAI). BiB. 2010;180:1970.

34. Watson D, Clark LA, Tellegen A. Development and validation of brief measures of positive and negative affect: the PANAS scales. J Pers Soc Psychol. 1988;54(6):1063-70.

35. Jackson SA, Martin AJ, Eklund RC. Long and short measures of flow: the construct validity of the FSS-2, DFS-2, and new brief counterparts. J Sport Exerc Psychol. 2008;30(5):561-87.

36. Wu H-S, Lin L-C, Wu S-C, Lin J-G. The psychologic consequences of chronic dyspnea in chronic pulmonary obstruction disease: the effects of acupressure on depression. J Altern Complement Med N Y N. 2007;13(2):253-61

37. Davison GC, Williams ME, Nezami E, Bice TL, DeQuattro VL. Relaxation, reduction in angry articulated thoughts, and improvements in borderline hypertension and heart rate. J Behav Med. 1991;14(5):453-68.

38. von Leupoldt A, Taube K, Schubert-Heukeshoven S, Magnussen H, Dahme B. Distractive auditory stimuli reduce the unpleasantness of dyspnea during exercise in patients with COPD. Chest. 2007:132(5):1506-12.

39. Gift AG, Moore T, Soeken K. Relaxation to reduce dyspnea and anxiety in COPD patients. Nurs Res. 1992:41(4):242-6.

40. Santana MJ, S-Parrilla J, Mirus J, Loadman M, Lien DC, Feeny D. An assessment of the effects of lyengar yoga practice on the health-related quality of life of patients with chronic respiratory diseases: a pilot study. Can Respir J. 2013;20(2):e17-23.

\section{Ready to submit your research? Choose BMC and benefit from:}

- fast, convenient online submission

- thorough peer review by experienced researchers in your field

- rapid publication on acceptance

- support for research data, including large and complex data types

- gold Open Access which fosters wider collaboration and increased citations

- maximum visibility for your research: over $100 \mathrm{M}$ website views per year

At BMC, research is always in progress.

Learn more biomedcentral.com/submissions 